\title{
Ethnic variations in asthma hospital admission, readmission and death: a retrospective, national cohort study of 4.62 million people in Scotland
}

Aziz Sheikh ${ }^{1,2,3^{*}}$, Markus F. C. Steiner ${ }^{4}$, Genevieve Cezard ${ }^{1}$, Narinder Bansal ${ }^{1,5}$, Colin Fischbacher ${ }^{1,6}$, Colin R. Simpson ${ }^{1,2}$, Anne Douglas ${ }^{1}$, and Raj Bhopal ${ }^{1}$ on behalf of the SHELS researchers

\begin{abstract}
Background: Our previous meta-analysis found that South Asians and Blacks in the UK were at a substantially increased risk of hospital admission from asthma. These estimates were, however, derived from pooling data from a limited number of now dated studies, confined to only three very broad ethnic groups (i.e. Whites, South Asians and Blacks) and failed to take account of possible sex-related differences in outcomes within these ethnic groups. We undertook the first study investigating ethnic variations in asthma outcomes across an entire population.

Methods: This retrospective 9-year cohort study linked Scotland's hospitalisation/death records on asthma to the 2001 census (providing ethnic group). We calculated age, country of birth and Scottish Index of Multiple Deprivation adjusted incident rate ratios (IRRs) for hospitalisation or death by sex for the period May 2001-2010. We calculated hazard ratios (HRs) for asthma readmission and subsequent asthma death.

Results: We were able to link data on 4.62 million people (91.8 \% of the Scottish population), yielding over 38 million patient-years of data, 1,845 asthma deaths, 113,795 first asthma admissions, and 107,710 readmissions (40,075 of which were for asthma). There were substantial ethnic variations in the rate of hospitalisation/death in both males and females. When compared to the reference Scottish White population, the highest age-adjusted rates were in Pakistani males $(\operatorname{IRR}=1.59 ; 95 \% \mathrm{Cl}, 1.30-1.94)$ and females (IRR $=1.50 ; 95 \% \mathrm{Cl}, 1.06-2.11)$ and Indian males (IRR $=1.34$; $95 \% \mathrm{Cl}, 1.16-1.54)$, and the lowest were seen in Chinese males (IRR $=0.62 ; 95 \% \mathrm{Cl}, 0.41-0.94)$ and females $(\mathrm{IRR}=0.49 ; 95 \% \mathrm{Cl}, 0.39-0.61)$.

Conclusion: There are very substantial ethnic variations in hospital admission/deaths from asthma in Scotland, with Pakistanis having the worst and Chinese having the best outcomes. Cultural factors, including self-management and health seeking behaviours, and variations in the quality of primary care provision are the most likely explanations for these differences and these now need to be formally investigated.
\end{abstract}

Keywords: Asthma, Death, Epidemiology, Ethnic variations, Hospital admission

\footnotetext{
* Correspondence: aziz.sheikh@ed.ac.uk

${ }^{1}$ Edinburgh Migration, Ethnicity and Health Research Group, Usher Institute of Population Health Sciences and Informatics, The University of Edinburgh, Teviot Place, Edinburgh EH8 9AG, UK

${ }^{2}$ Asthma UK Centre for Applied Research, Usher Institute of Population Health Sciences and Informatics, The University of Edinburgh, Edinburgh, UK Full list of author information is available at the end of the article
} 


\section{Background}

Asthma is now one of the most common long-term disorders in the world, with global estimates indicating that at least 300 million people have asthma [1]. The landmark International Study of Asthma and Allergies in Childhood (ISAAC) and the European Community Respiratory Health Survey (ECRHS) studies demonstrated substantial national variations in asthma prevalence, with evidence suggesting that the UK ranks as one of the highest prevalence countries in the world $[2,3]$. The recent UK National Review of Asthma Deaths has found persistent problems with poor asthma care and substantial, potentially preventable morbidity and mortality [4]. Investigations conducted within the UK suggest that Scotland has a particularly high morbidity from asthma, for reasons that remain poorly understood [5].

There are, as yet, only a limited number of withincountry investigations of ethnic differences in asthma. The majority of this literature comes from the US and this has shown that African-Americans are at increased risk of exacerbations, hospital attendances, near death episodes, and mortality [6-9]. This has led to recent substantial investments $(\$ 23 \mathrm{~m})$ to reduce asthma disparities through the Patient-Centered Outcomes Research Institute [10]. A previous systematic review and meta-analysis investigating ethnic variations in asthma outcomes in the UK found that South Asians (odds ratio $(\mathrm{OR})=2.9 ; 95 \% \mathrm{CI}, 2.4-3.4$ ) and Blacks $(\mathrm{OR}=2.1 ; 95 \% \mathrm{CI}, 1.8-2.5)$ were at substantially increased risk of hospital admission from asthma when compared to White European-origin populations [11]. This synthesis was, however, of only a limited number $(\mathrm{n}=13)$ of now dated studies (undertaken in the 1980-90s), and the summary estimates were therefore only available for three broad ethnic groups, namely: Whites, Blacks and South Asians. The opportunities for exploring heterogeneity within these three groups or indeed investigating differences between males and females in these populations were therefore limited [12].
There is a need for a more contemporaneous, comprehensive investigation into within-country ethnic variations in asthma and asthma outcomes. We report on the first national cohort study to investigate the hypothesis that there are substantial ethnic variations in hospitalisations and deaths from asthma in the Scottish population.

\section{Methods}

\section{Ethics and permissions}

We obtained ethical approval from the Scotland A Research Ethics Committee. We also obtained approvals from Scotland's Privacy Advisory Committee and the Community Health Index Advisory Group, which are charged with considering the appropriate use of potentially identifiable patient data. Access to data, analyses and release of outputs followed a pre-specified protocol, which included rounding of all count numbers to the nearest five to ensure confidentiality and to prevent disclosure of any potentially identifying data. This included suppression of data if there was any risk that individual patients may be identifiable $(\mathrm{n}<6)$. All outputs were reviewed by a National Records of Scotland data disclosure committee.

\section{Overview of methods and data linkage}

The methods of the Scottish Health and Ethnicity Linkage Study (SHELS) have previously been described in detail and we therefore confine ourselves here to providing a brief overview of the procedures used [13]. In summary, we linked National Health Service (NHS) Scotland's hospital discharge and death records (SMR01) to the 2001 census using probabilistic linkage methods creating a unique link between the encrypted Community Health Index and census number, thereby creating a national retrospective cohort. An overview of the linkage techniques is shown in Fig. 1. All personal identifiers were then removed from the linked dataset.

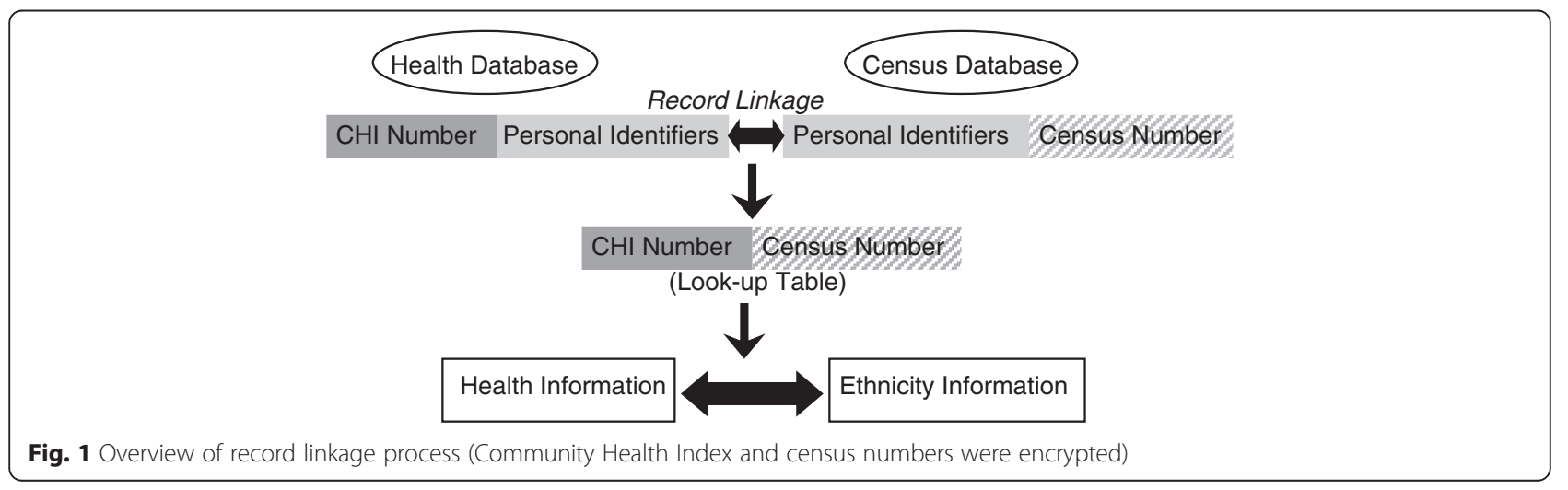




\section{Ethnicity data}

Ethnic categories were derived from the 14 groups in the 2001 Scottish Census (Box 1) and reported following the principles of the census (including capitalisation of ethnic group labels) [14]; when discussing the work of others, however, we used the labels assigned by authors in their publications. Given small populations, we combined Bangladeshis with Other South Asians and the Caribbean, African and Black Scottish or Other Black as an African origin group, thus giving rise to the nine categories of ethnicity that were studied and reported on.

\section{Asthma outcomes}

We had three outcomes of interest: (1) first hospitalisation or death from asthma following inception of the cohort in May 2001, which was our primary outcome and is henceforth referred to as 'first asthma events' (group 1); (2) asthma readmission among survivors of group 1; and (3) asthma death among survivors of group 1 . We identified hospitalisations and deaths for asthma during the period May 2001-April 2010 using relevant International Classification of Disease codes (i.e. ICD-9: 493 and 493.9, and ICD-10: J45 and J46). To take account of the chronic nature of asthma, we did not exclude those with admissions before May 2001 [15]. Our 'first asthma events' were therefore initial episodes within the cohort study, which may or may not correspond with the first ever episodes of hospitalisation.

\section{Demographic and socioeconomic factors}

Census data included age, sex, Scottish Index of Multiple Deprivation (SIMD), and country of birth (CoB). SIMD is an area-based socioeconomic measure that uses 38 indicators across nine domains including health to rank

\begin{tabular}{l} 
Box 1: Scotland 2001 Census ethnic groups \\
\hline White Scottish \\
Other White British \\
White Irish \\
Other White \\
Any mixed background \\
Indian \\
Pakistani \\
Bangladeshi \\
Other South Asian \\
Caribbean \\
African \\
Black Scottish or Other Black \\
Chinese \\
Other ethnic group
\end{tabular}

areas based on full postcode [16]. The SIMD is known to be associated with health outcomes whether it includes, or excludes, the health domains.

\section{Analysis}

Our detailed analysis plan specified that, because of concerns around small numbers and the associated risk of disclosure, analysis of hospitalisation and death would only be separately undertaken if deaths were at least $20 \%$ of the total numbers. We also pre-specified that if this was not the case, the first of either of these two events would be included, thereby ensuring that we included community deaths.

Using Poisson regression models with robust variance we calculated age-adjusted rates of first asthma events (i.e. outcome (1) specified above) per 100,000 person years and incidence rate ratios (IRR) with $95 \%$ confidence intervals (CI) by sex, this being undertaken because of the known sex variations in asthma epidemiology and outcomes. The person-years-at-risk denominators were calculated after censoring for deaths, asthma-related hospitalisations and transfers of patients out of NHS Scotland (i.e. to other parts of the UK), as appropriate.

The age-adjusted sex-stratified analysis was the primary analysis. We then examined the effect of adjustment by socioeconomic variables and $\mathrm{CoB}$ separately and in combination. We explored the association between eight measures of socioeconomic status (i.e. individual educational level, household educational level, individual National Statistics Socioeconomic Classification, household National Statistics Socioeconomic Classification, SIMD quintile, car ownership, household tenure, and economic activity) and health outcomes following our published approach, and we selected SIMD (quintiles), which was available for everyone; in contrast, other relevant variables were not collected for younger and older age groups [17]. Our analysis used the quintile of socioeconomic deprivation. We adjusted for birth within or outside the UK to explore whether this altered IRRs (there were not enough events for stratified analysis by $\mathrm{CoB}$ and ethnicity).

We undertook survival analysis and calculated hazard ratios (HRs) for death or readmission with asthma following hospitalisation (outcomes (2) and (3) as specified above, censoring for death) using Cox proportional hazard models, checking the proportional hazards assumption with the graphical method using $\log -\log (\ln \{-\ln ($ survival $)\})$ plots. Analysis was undertaken using SAS v9.3 (SAS Institute Inc., Cary, North Carolina, USA).

\section{Results}

Overview of the cohort

Scotland had an enumerated population of 4.9 million on census day (29 April 2001); $52 \%$ of the population 
was female and $89 \%$ was White Scottish (Table 1). We were able to link data on 4.62 million individuals ( $94.9 \%$ of the eligible population), yielding $38,216,530$ patientyears of data over the 9-year study period (Fig. 2). We successfully linked data on at least $85 \%$ of people from each ethnic group of interest (Tables 1 and 2).

\section{First asthma events}

There was a total of 113,790 first asthma admissions ( $\mathrm{n}=67,080 ; 59 \%$ in females) and 505 deaths with asthma diagnosis and no prior hospital admission for asthma (59 \% in females). There were substantial ethnic variations in first asthma events in both males and females (Fig. 3). Age-adjusted incidence rates for a first asthma event in the total population were 256.6 (95 \% CI, 208.1-316.3) per 100,000 person years in males and 338.1 (288.7-395.9) in females.

When compared to the White Scottish reference population, the highest age-adjusted rates were in Pakistani males $(\mathrm{IRR}=1.59 ; 95 \% \mathrm{CI}, 1.30-1.94)$ and females (IRR = 1.50; $95 \% \mathrm{CI}, 1.06-2.11)$ and Indian males (IRR = 1.34; $95 \%$ CI, 1.16-1.54), and the lowest were seen in Chinese males (IRR $=0.62$; $95 \% \mathrm{CI}, 0.41-0.94)$ and females (IRR = 0.49; $95 \%$ CI, 0.39-0.61) followed by 'Other White' males $(\mathrm{IRR}=0.77 ; 95 \% \mathrm{CI}, 0.64-0.92)$ and females (IRR = 0.81; $95 \%$ CI, 0.70-0.93). Further adjustment for SIMD and $\mathrm{CoB}$ did not substantially modify the observed patterns (Table 3).

\section{Asthma readmissions among survivors of a first asthma event}

There were 107,710 readmissions in the cohort; 40,075 of these readmissions were for asthma (37 \% of all readmissions for asthma), with the majority of these occurring in females ( $n=24,660 ; 61.5 \%)$. Increased rates of readmission were seen in Any Mixed Background males $(\mathrm{HR}=1.37$; $95 \% \mathrm{CI}, 1.02-1.83)$ and African Origin females (HR $=1.56$, $95 \% \mathrm{CI}, 1.11-2.20)$. Other than this, no clear patterns were apparent, this possibly reflecting the relatively small number of readmissions within most of the minority ethnic groups and the associated imprecision of the HR estimates obtained (Table 4).

\section{Asthma deaths among survivors of a first asthma event}

In total, there were 1,340 asthma deaths recorded in those who survived the first asthma event. As death was an infrequent occurrence ( $0.4 \%$ of first asthma events) data on survival were suppressed for most ethnic groups because of the possible risk of disclosure. The available data on Other White British males ( $\mathrm{HR}=0.69 ; 95 \% \mathrm{CI}$, 0.45-1.06) and Other White British ( $\mathrm{HR}=0.93 ; 95 \% \mathrm{CI}$, 0.70-1.23), White Irish (HR $=1.08 ; 95 \% \mathrm{CI}, 0.58-2.01)$ and Other White $(\mathrm{HR}=1.27$; $95 \% \mathrm{CI}, 0.63-2.55)$ females was imprecisely estimated.

\section{Discussion}

\section{Statement of principal findings}

This national investigation into risk of poor asthma outcomes has found substantial ethnic variations in the rates of hospital admission and death between ethnic groups in Scotland. When compared to the reference White Scottish population, people of South Asian descent (i.e. Pakistani, Indian and Other South Asians) had 20-50 \% increased rates of hospitalisation from asthma, whereas people of Chinese origin had 30-40\% lower rates. Comparing the Chinese with the Pakistani populations revealed a striking 2-3-fold variation in rates of admission. However, despite accruing over 38 million

Table 1 Baseline characteristics of study population

\begin{tabular}{|c|c|c|c|c|c|c|c|c|c|c|c|}
\hline & \multicolumn{2}{|l|}{ Census } & \multicolumn{2}{|c|}{$\begin{array}{l}\text { First asthma admissions } \\
\text { and deaths }\end{array}$} & \multicolumn{2}{|l|}{ Male } & \multicolumn{2}{|l|}{ Female } & \multirow{2}{*}{$\begin{array}{l}\% \text { Female in each group } \\
\%\end{array}$} & \multicolumn{2}{|c|}{$\begin{array}{l}\text { First asthma admissions } \\
\text { incidence from } 2001\end{array}$} \\
\hline & $\mathrm{n}$ & $\%$ & $\mathrm{n}$ & $\%$ & $\mathrm{n}$ & $\%$ & n & $\%$ & & $\mathrm{n}$ & $\%$ \\
\hline White Scottish & $4,088,125$ & 88.6 & 102,285 & 89.9 & 41,955 & 89.8 & 60,330 & 89.9 & $59.0 \%$ & 86,930 & 89.9 \\
\hline Other White British & 334,985 & 7.3 & 7,555 & 6.6 & 3,005 & 6.4 & 4,550 & 6.8 & $60.2 \%$ & 6,515 & 6.7 \\
\hline White Irish & 43,505 & 0.9 & 985 & 0.9 & 390 & 0.8 & 590 & 0.9 & $60.2 \%$ & 825 & 0.9 \\
\hline Other White & 65,655 & 1.4 & 1,030 & 0.9 & 410 & 0.9 & 620 & 0.9 & $60.2 \%$ & 895 & 0.9 \\
\hline Any mixed background & 11,110 & 0.2 & 265 & 0.2 & 115 & 0.2 & 150 & 0.2 & $56.6 \%$ & 220 & 0.2 \\
\hline Indian & 12,335 & 0.3 & 305 & 0.3 & 160 & 0.3 & 150 & 0.2 & $48.4 \%$ & 225 & 0.2 \\
\hline Pakistani & 25,630 & 0.6 & 840 & 0.7 & 415 & 0.9 & 420 & 0.6 & $50.3 \%$ & 655 & 0.7 \\
\hline Other South Asian & 6,510 & 0.1 & 155 & 0.1 & 80 & 0.2 & 75 & 0.1 & $48.4 \%$ & 135 & 0.1 \\
\hline African origin & 6,335 & 0.1 & 120 & 0.1 & 50 & 0.1 & 70 & 0.1 & $58.3 \%$ & 105 & 0.1 \\
\hline Chinese & 13,205 & 0.3 & 145 & 0.1 & 75 & 0.2 & 70 & 0.1 & $48.3 \%$ & 120 & 0.1 \\
\hline All other ethnic groups & 7,715 & 0.2 & 105 & 0.1 & 50 & 0.1 & 55 & 0.1 & $52.4 \%$ & 90 & 0.1 \\
\hline Total & $4,615,105$ & & 113,790 & & 46,710 & & 67,080 & & $59.0 \%$ & 96,710 & \\
\hline
\end{tabular}




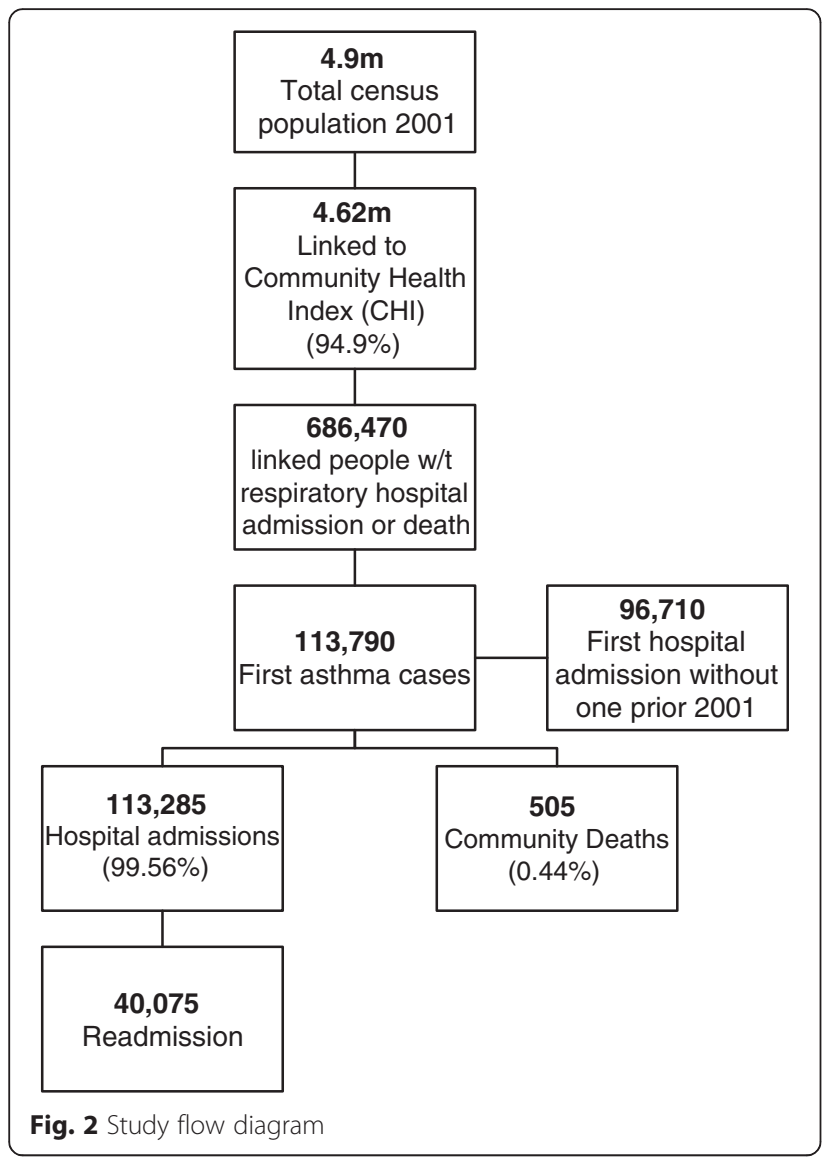

person-years of data during the 9-year study period, we obtained only imprecise estimates of the rates of death and readmission in survivors, this reflecting the relative infrequency of these outcomes in many of the populations studied.

\section{Strengths and limitations}

This is, as far as we are aware, the first national investigation into within-country ethnic variations in asthma outcomes and it has provided some of the first estimates of asthma outcomes in a number of sub-sections of the UK population (e.g. White Irish and Chinese) [11]. Additional key strengths of this work include the substantial number of patient-years of data available, which offered the possibility to study a large number of hospitalisations for asthma - the main focus of our study. Through linking to the 2001 Census we were able to simultaneously adjust for age, $\mathrm{CoB}$ and socioeconomic status [18]. The decision to stratify reporting by sex was important given the marked overall increased rate of admission, readmission and mortality in females. Furthermore, in keeping with best practice, our analysis strategy was written and agreed prior to data analysis.

Nonetheless, we acknowledge limitations, including the fact that we were not able to link data on the entire Scottish population, differential rates in linkage between ethnic groups which may have introduced bias, the fact that we were not fully able to take into account emigration from Scotland, that event numbers in some nonWhite ethnic groups were small (particularly limiting for survival analysis), and that, because analysis of data on small groups potentially risked disclosing identity, we were not able to report on mortality data for the majority of the groups studied. Missing data may also have introduced the possibility of bias. It is impossible to know how much missing data there was overall, but we believe that this is likely to be small. This missing data could have arisen for three possible reasons: (1) those who did not participate in the census (estimated $<5 \%$ ); (2) those for whom it was not possible to link census and hospitalisation and mortality data (estimated $<5 \%$ at date of

Table 2 Further baseline characteristics of study population

\begin{tabular}{|c|c|c|c|c|c|c|c|c|c|c|c|c|c|}
\hline & \multirow[b]{2}{*}{$\mathrm{n}$} & \multicolumn{4}{|c|}{ Age groups } & \multirow{2}{*}{$\begin{array}{l}\text { Age, years } \\
\text { Mean }\end{array}$} & \multicolumn{2}{|c|}{ Country of birth } & \multicolumn{5}{|c|}{ SIMD quintiles } \\
\hline & & $<20$ & 20 to $<40$ & 40 to $<60$ & $60+$ & & UK born & Outside UK & 1 & 2 & 3 & 4 & 5 \\
\hline White Scottish & 102,285 & $23.7 \%$ & $21.6 \%$ & $26.9 \%$ & $27.8 \%$ & 41.7 & $99.1 \%$ & $0.9 \%$ & $26.2 \%$ & $23.6 \%$ & $20.5 \%$ & $16.7 \%$ & $13.0 \%$ \\
\hline Other White British & 7,555 & $11.2 \%$ & $21.0 \%$ & $34.0 \%$ & $33.9 \%$ & 48.8 & $95.8 \%$ & $4.2 \%$ & $12.0 \%$ & $16.3 \%$ & $26.8 \%$ & $25.7 \%$ & $19.1 \%$ \\
\hline White Irish & 985 & $7.1 \%$ & $17.3 \%$ & $32.5 \%$ & $43.1 \%$ & 53.6 & $99.0 \%$ & $1.0 \%$ & $27.9 \%$ & $24.9 \%$ & $19.8 \%$ & $14.2 \%$ & $13.2 \%$ \\
\hline Other White & 1,030 & $18.9 \%$ & $22.8 \%$ & $27.7 \%$ & $30.6 \%$ & 44.3 & $36.4 \%$ & $63.6 \%$ & $16.6 \%$ & $21.5 \%$ & $22.0 \%$ & $19.5 \%$ & $20.5 \%$ \\
\hline Any mixed background & 265 & $54.7 \%$ & $17.0 \%$ & $17.0 \%$ & $11.3 \%$ & 25.6 & $83.0 \%$ & $17.0 \%$ & $27.8 \%$ & $18.5 \%$ & $16.7 \%$ & $18.5 \%$ & $18.5 \%$ \\
\hline Indian & 305 & $27.9 \%$ & $26.2 \%$ & $24.6 \%$ & $21.3 \%$ & 36.9 & $51.6 \%$ & $48.4 \%$ & $13.1 \%$ & $21.3 \%$ & $11.5 \%$ & $18.0 \%$ & $36.1 \%$ \\
\hline Pakistani & 840 & $33.5 \%$ & $21.6 \%$ & $28.1 \%$ & $16.8 \%$ & 33.6 & $46.4 \%$ & $53.6 \%$ & $17.4 \%$ & $28.7 \%$ & $13.8 \%$ & $17.4 \%$ & $22.8 \%$ \\
\hline Other South Asian & 155 & $32.3 \%$ & $19.4 \%$ & $32.3 \%$ & $16.1 \%$ & 34.8 & $51.6 \%$ & $48.4 \%$ & $22.6 \%$ & $22.6 \%$ & $12.9 \%$ & $19.4 \%$ & $22.6 \%$ \\
\hline African origin & 120 & $41.7 \%$ & $25.0 \%$ & $25.0 \%$ & $8.3 \%$ & 30.9 & $62.5 \%$ & $37.5 \%$ & $29.2 \%$ & $20.8 \%$ & $16.7 \%$ & $20.8 \%$ & $12.5 \%$ \\
\hline Chinese & 145 & $48.3 \%$ & $17.2 \%$ & $20.7 \%$ & $13.8 \%$ & 29.5 & $55.2 \%$ & $44.8 \%$ & $20.7 \%$ & $13.8 \%$ & $10.3 \%$ & $20.7 \%$ & $34.5 \%$ \\
\hline All Other Ethnic group & 105 & $33.3 \%$ & $28.6 \%$ & $28.6 \%$ & $9.5 \%$ & 33.8 & $33.3 \%$ & $66.7 \%$ & $19.0 \%$ & $19.0 \%$ & $19.0 \%$ & $14.3 \%$ & $28.6 \%$ \\
\hline Total & 113,790 & $22.9 \%$ & $21.5 \%$ & $27.4 \%$ & $28.2 \%$ & 42.1 & $97.6 \%$ & $2.4 \%$ & $25.1 \%$ & $23.1 \%$ & $20.8 \%$ & $17.3 \%$ & $13.7 \%$ \\
\hline
\end{tabular}




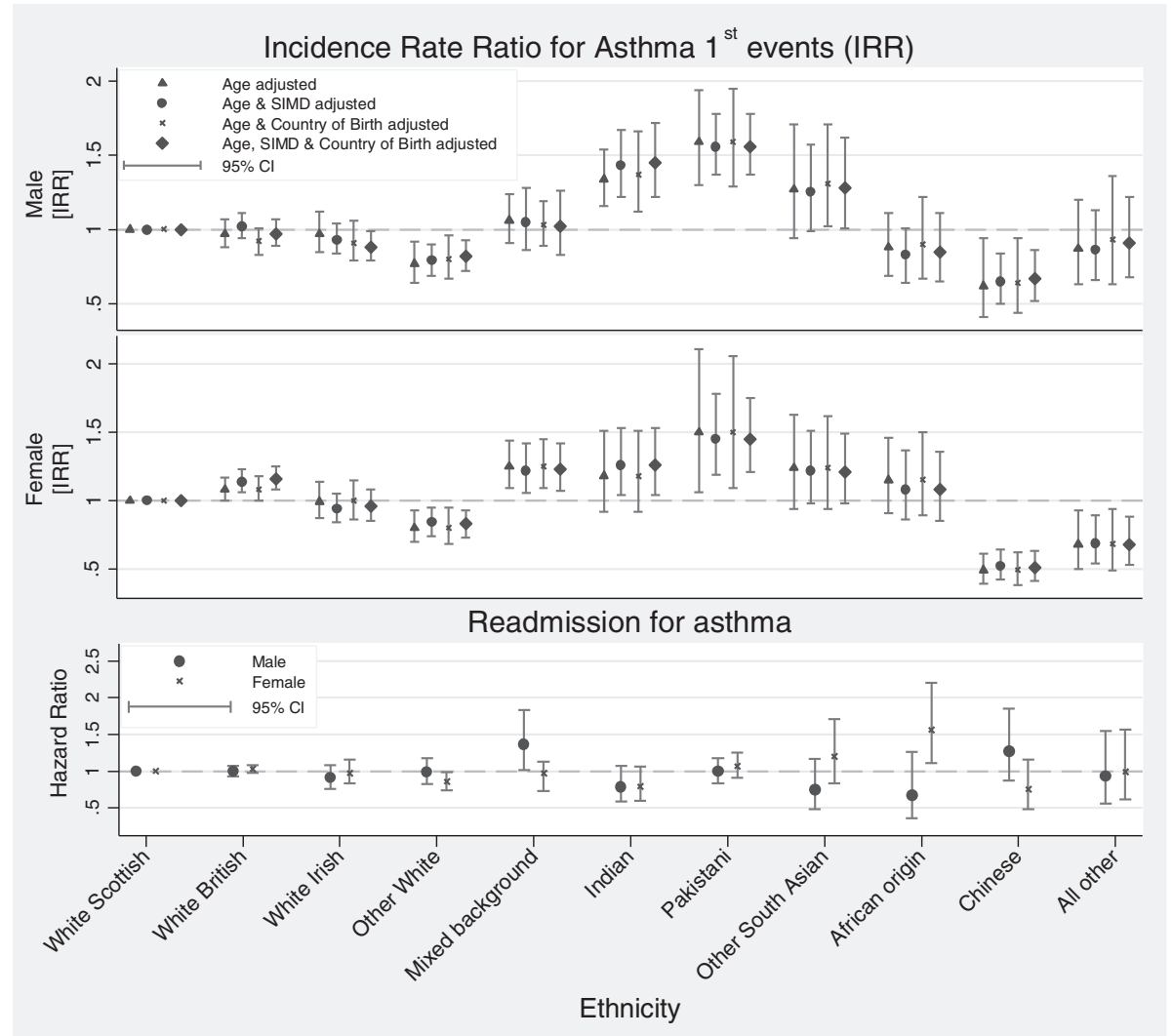

Fig. 3 Summary data for ethnic variations in incidence rate ratios of first asthma events and hazard ratios of readmissions

census, and increases with length of time from the census due to immigration and births); and (3) those admitted into private hospitals that did not then convey this information to the Information Services Division of NHS National Services Scotland ( $<1 \%)$. We attempted to censor those who migrated, but it was not possible to identify the likely small proportion of people who were not registered with NHS Scotland who emigrated or those who were registered with NHS Scotland but who emigrated outside of the UK. Finally, we were only able to adjust for a limited number of potential confounders in the relationship between ethnicity and asthma outcome and, as discussed below, future work needs to consider the impact of wider organisational, care-related and behavioural factors which may help to explain these variations.

\section{Interpreting the findings in the context of the wider literature and implications for future research}

These findings confirm the poor outcomes previously noted for UK South Asians, but were not as marked, possibly reflecting the relatively high rate of hospitalisation in the reference Scottish White population and/or the reduced risk of bias resulting from the fact that we were able to study the entire population [11]. These data also reveal that not all ethnic minority groups experience poor outcomes when compared with the reference population. In particular, the rate of asthma admission in Chinese-origin males and females were markedly lower than that seen in the White Scottish population. Given that good outcomes in the Scottish Chinese population have also been noted for a range of other long-term conditions such as heart failure [19], there is a need to investigate whether this is due to Chinese populations having comparatively better health, lower use of health services, or a combination of both of these factors.

There is now a need to understand the reasons underpinning these striking variations in outcomes. Possibilities include biological differences in disease severity, the impact of migration (although we did not find any effect of adjusting for $\mathrm{CoB}$ ) [18], and the greater prevalence of atopy noted in South Asian children in the UK [20]. Another potentially important explanatory consideration is differences in over-crowding with the associated risk of admissions triggered by viral upper respiratory tract infections. Differences in health professional management including access to and quality of primary care (such as vaccination rates, prescribing and use of supported selfmanagement plans) [21] and cultural factors, including differences in personal beliefs, self-management (in particular, 
Table 3 Incidence rates, incidence rate ratios (IRRs), and hazard ratio estimates per 100,000 population per year (PY) for first asthma hospital admission or death. IRRs are age adjusted and rate ratios are subsequently Scottish Index for Multiple Deprivation (SIMD) and country of birth (COB) adjusted, with $95 \%$ confidence intervals (CIs), by ethnic group, for the population in Scotland

\begin{tabular}{|c|c|c|c|c|c|c|c|}
\hline \multirow[t]{2}{*}{ Ethnic group } & \multirow[t]{2}{*}{$\begin{array}{l}\text { First asthma } \\
\text { event }^{\mathrm{a}}\end{array}$} & \multirow[t]{2}{*}{ PY at risk ${ }^{\mathrm{b}}$} & \multirow[t]{2}{*}{$\begin{array}{l}\text { Age adjusted incidence rates } \\
\text { (per 100,000 PY) and } 95 \% \mathrm{Cls}^{\mathrm{c}}\end{array}$} & \multirow{2}{*}{$\begin{array}{l}\text { Age-adjusted } \\
\text { IRRs }^{d} \\
\text { IRR and } 95 \% \mathrm{Cl}\end{array}$} & \multirow{2}{*}{$\begin{array}{l}\text { Age- and SIMD-adjusted } \\
\text { IRR } \\
\text { IRR and } 95 \% \mathrm{Cl}\end{array}$} & \multirow{2}{*}{$\begin{array}{l}\text { Age- and CoB-adjusted } \\
\text { IRR }^{d} \\
\text { IRR and } 95 \% \mathrm{Cl}\end{array}$} & \multirow{2}{*}{$\begin{array}{l}\text { Age-, SIMD- and CoB-adjusted } \\
\text { IRR }^{d} \\
\text { IRR and } 95 \% \mathrm{Cl}\end{array}$} \\
\hline & & & & & & & \\
\hline \multicolumn{8}{|l|}{ Males } \\
\hline White Scottish & 41,955 & $16,325,930$ & 257.0 & $1.00()$. & $1.00()$. & $1.00()$. & $1.00()$. \\
\hline Other White British & 3,005 & $1,244,330$ & $249.7(227.7-276.9)$ & $0.97(0.88-1.07)$ & $1.02(0.94-1.11)$ & $0.92(0.83-1.01)$ & $0.97(0.89-1.069)$ \\
\hline White Irish & 390 & 160,090 & $250.2(217.4-287.8)$ & $0.97(0.85-1.12)$ & $0.93(0.84-1.04)$ & $0.91(0.79-1.06)$ & $0.88(0.79-0.99)$ \\
\hline Other White & 410 & 223,900 & $196.5(164.8-238.4)$ & $0.78(0.64-0.92)$ & $0.79(0.69-0.90)$ & $0.80(0.67-0.96)$ & $0.82(0.72-0.93)$ \\
\hline $\begin{array}{l}\text { Any mixed } \\
\text { background }\end{array}$ & 115 & 42,835 & $273.2(235.0-320.4)$ & $1.06(0.91-1.24)$ & $1.05(0.86-1.28)$ & $1.03(0.89-1.19)$ & $1.02(0.83-1.26)$ \\
\hline Indian & 160 & 50,445 & $344.5(300.3-397.8)$ & $1.34(1.16-1.54)$ & $1.43(1.22-1.67)$ & $1.37(1.12-1.66)$ & $1.45(1.22-1.72)$ \\
\hline Pakistani & 420 & 109,375 & $408.1(336.3-501.8)$ & $1.59(1.30-1.94)$ & $1.56(1.37-1.78)$ & 1.59 (1.29-1.95) & $1.56(1.37-1.78)$ \\
\hline Other South Asian & 80 & 27,265 & $327.3(244.6-441.3)$ & $1.27(0.94-1.71)$ & $1.25(0.99-1.57)$ & $1.31(1.02-1.71)$ & $1.28(1.01-1.62)$ \\
\hline African Origin & 50 & 25,020 & $225.3(178.4-286.6)$ & $0.88(0.69-1.11)$ & $0.83(0.64-1.01)$ & $0.90(0.67-1.22)$ & $0.85(0.65-1.11)$ \\
\hline Chinese & 75 & 52,825 & $159.1(105.6-241.5)$ & $0.62(0.41-0.94)$ & $0.65(050-0.84)$ & $0.64(0.44-0.94)$ & $0.67(0.52-0.86)$ \\
\hline All Other Ethnic Group & 50 & 25,650 & $223.5(162.1-310.6)$ & $0.87(0.63-1.20)$ & $0.86(0.66-1.13)$ & $0.93(0.63-1.36)$ & $0.91(0.68-1.22)$ \\
\hline \multirow[t]{2}{*}{ Ethnic group } & \multirow[t]{2}{*}{$\begin{array}{l}\text { First asthma } \\
\text { event }^{\mathrm{a}}\end{array}$} & \multirow[t]{2}{*}{ PY at risk ${ }^{b}$} & \multirow[t]{2}{*}{$\begin{array}{l}\text { Age-adjusted incidence rates (for } 100,000 \\
\text { PY) }\end{array}$} & Age-adjusted IRR ${ }^{d}$ & $\begin{array}{l}\text { Age- and SIMD-adjusted } \\
\text { IRR }^{d}\end{array}$ & $\begin{array}{l}\text { Age- and CoB-adjusted } \\
\mathbb{R R}^{\mathrm{d}}\end{array}$ & $\begin{array}{l}\text { Age-, SIMD- and CoB-adjusted } \\
\text { IRR }^{d}\end{array}$ \\
\hline & & & & IRR and $95 \% \mathrm{Cl}$ & IRR and $95 \% \mathrm{Cl}$ & IRR and $95 \% \mathrm{Cl}$ & IRR and $95 \% \mathrm{Cl}$ \\
\hline \multicolumn{8}{|l|}{ Females } \\
\hline White Scottish & 60,330 & $17,830,550$ & 338.3 & $1.00()$. & $1.00()$. & $1.00()$. & $1.00()$. \\
\hline Other White British & 4,550 & $1,334,530$ & $365.4(339.3-397.6)$ & $1.08(1.00-1.17)$ & $1.14(1.06-1.23)$ & $1.08(1.00-1.18)$ & $1.16(1.08-1.25)$ \\
\hline White Irish & 590 & 178,670 & $335.9(295.7-387.0)$ & $0.99(0.87-1.14)$ & $0.94(0.84-1.05)$ & $1.00(0.86-1.15)$ & $0.96(0.85-1.08)$ \\
\hline Other White & 620 & 259,410 & $271.6(237.3-315.5)$ & $0.80(0.70-0.93)$ & $0.84(0.74-0.95)$ & $0.80(0.68-0.95)$ & $0.83(0.73-0.93)$ \\
\hline $\begin{array}{l}\text { Any mixed } \\
\text { background }\end{array}$ & 150 & 46,190 & $424.1(369.5-489.7)$ & $1.25(1.09-1.44)$ & $1.22(1.06-1.42)$ & $1.25(1.09-1.45)$ & $1.23(1.07-1.42)$ \\
\hline Indian & 150 & 45,810 & $398.1(311.2-512.3)$ & $1.18(0.92-1.51)$ & $1.26(1.04-1.53)$ & $1.18(0.92-1.51)$ & $1.26(1.04-1.53)$ \\
\hline Pakistani & 420 & 107,485 & $506.1(361.1-718.0)$ & $1.50(1.06-2.11)$ & $1.45(1.19-1.78)$ & $1.50(1.09-2.06)$ & $1.45(1.21-1.75)$ \\
\hline Other South Asian & 75 & 22,205 & $418.9(318.9-553.6)$ & $1.24(0.94-1.63)$ & $1.22(0.98-1.51)$ & $1.24(0.94 .1 .62)$ & $1.21(0.98-1.49)$ \\
\hline African Origin & 70 & 22,215 & $390.4(309.7-495.0)$ & $1.15(0.91-1.46)$ & $1.08(0.86-1.37)$ & $1.15(0.89-1.50)$ & $1.08(0.85-1.36)$ \\
\hline Chinese & 70 & 52,660 & $165.3(132.5-207.5)$ & $0.49(0.39-0.61)$ & $0.52(0.42-0.64)$ & $0.49(0.38-0.62)$ & $0.51(0.41-0.63)$ \\
\hline All Other Ethnic Group & 55 & 29,145 & $230.6(170.4-314.1)$ & $0.68(0.50-0.93)$ & $0.69(0.54-0.89)$ & $0.68(0.49-0.94)$ & $0.68(0.53-0.88)$ \\
\hline
\end{tabular}

${ }^{\mathrm{a}}$ First event within the period 1st May 2001 to 30th April 2010, with no look back previous to this period

bover 9-year period between 1st May 2001 and 30th April 2010

Over 9-year period between 1 st May 2001 and 30th April 2010
CPoisson rates are derived with age adjustment using the true White Scottish rate

Incidence rate ratios are calculated using Poisson regression models with robust variance. The White Scottish population at the 2001 census is the reference population 
Table 4 Hazard ratios (HRs) adjusted for age, relative to White Scottish of hospital readmission for asthma following a first hospital admission of asthma during the study period (i.e. 1/5/2001-31/4/2010) in men and women

\begin{tabular}{|c|c|c|c|c|}
\hline \multirow{3}{*}{ Ethnic group } & \multicolumn{2}{|l|}{ Males } & \multicolumn{2}{|l|}{ Females } \\
\hline & Number of readmissions & Overall readmission & Number of readmissions & Overall readmission \\
\hline & & $\mathrm{HR}$ and $95 \% \mathrm{Cl}$ & & $\mathrm{HR}$ and $95 \% \mathrm{Cl}$ \\
\hline White Scottish & 13,795 & $1.00()$. & 22,115 & $1.00()$. \\
\hline Other White British & 1,040 & $1.00(0.93-1.07)$ & 1,740 & $1.03(0.98-1.08)$ \\
\hline White Irish & 130 & $0.91(0.76-1.08)$ & 225 & $0.97(0.84-1.16)$ \\
\hline Other White & 140 & $0.99(0.83-1.18)$ & 200 & $0.86(0.74-0.99)$ \\
\hline Any mixed background & 45 & $1.37(1.02-1.83)$ & 50 & $0.97(0.73-1.13)$ \\
\hline Indian & 45 & $0.79(0.59-1.07)$ & 50 & $0.79(0.60-1.06)$ \\
\hline Pakistani & 145 & $1.00(0.84-1.18)$ & 170 & $1.07(0.91-1.25)$ \\
\hline Other South Asian & 20 & $0.75(0.49-1.17)$ & 30 & $1.20(0.84-1.71)$ \\
\hline African Origin & 10 & $0.68(0.36-1.26)$ & 35 & $1.56(1.11-2.20)$ \\
\hline Chinese & 25 & $1.27(0.87-1.85)$ & 20 & $0.76(0.49-1.16)$ \\
\hline All Other Ethnic Group & 15 & $0.93(0.56-1.55)$ & 20 & $0.99(0.62-1.57)$ \\
\hline
\end{tabular}

concordance with preventive therapies) and health-seeking behaviour, may also be important contributory factors [22]. US data have, for example, shown marked variations in the quality of ambulatory and emergency department asthma care, but comparable hospital-based care [23]. There is also a need to consider the possibility of systematic biases through investigating the impact of differential rates of linkage and emigration between ethnic groups [24].

Data on a number of potential explanatory variables are available in general practitioner records, and our plan is therefore to link the SHELS cohort with primary care data across Scotland. We have undertaken a feasibility pilot (data being prepared for publication) and other primary care data extractions [25], which shows that this is technically possible and that relevant data on, for example, smoking, vaccination and prescribing patterns can be obtained for future studies. A key priority for future work will be to investigate to what extent these variations in outcome can be explained by differences in lifestyle factors, health-seeking behaviours and/or the quality of primary care [21, 22, 26, 27]. Future work should also explore the possibility of interactions between ethnicity and socioeconomic status.

\section{Conclusions}

This study has provided compelling evidence of important national variations in rates of asthma hospital admissions/deaths across ethnic groups in Scotland. It seems likely that the majority of these variations are amenable to lifestyle and/or medical intervention in primary care, and a key near-term target should therefore be to reduce the risk of hospitalisation/death for all ethnic groups, but especially in Pakistani males and females and Indian males in Scotland.

\section{Availability of supporting data}

We do not have permission to share the underlying dataset as, due to security considerations, this needs to be analysed within the confines of a safe haven. Researchers should contact the principal investigator if they wish to explore the possibility of collaborative work.

\section{Abbreviations}

Cl: Confidence interval; CoB: Country of birth; HR: Hazard ratio; IRR: Incidence rate ratio; NHS: National Health Service; OR: Odds ratio; PY: Person years; SHELS: Scottish Health and Ethnicity Linkage Study; SIMD: Scottish Index of Multiple Deprivation.

\section{Competing interests}

The authors declare that they have no competing interests.

\section{Authors' contributions}

The authorship, the authorship by-line, and note of contributions follows SHELS policy on authorship. All authors served on the respiratory subgroup of SHELS which planned the work in detail. RB was the PI of SHELS; AS chaired the respiratory subgroup and led the writing of this manuscript; CF was a coinvestigator; CRS was a research collaborator; MFCS was clinical research fellow and lead analyst; GC was researcher and analyst; NB was the study coordinator and research fellow; and AD coordinated the project in the final phase and wrote a report on the respiratory analysis. All authors helped plan the study and/or analysis, interpret data, critically revise drafts of the manuscript and agreed submission of the final draft.

\section{Acknowledgements}

We thank our SHELS collaborators at NHS Information Services Division and at National Records Scotland and the SHELS Phase 3 Steering Group. We acknowledge input to this report from Jenny Holmes, SHELS Study assistant. AS was supported by The Commonwealth Fund, a private independent foundation based in New York City. The views presented here are those of the authors and not necessarily those of The Commonwealth Fund, its directors, officers, or staff. AS is Director of the Asthma UK Centre for Applied Research; he also acknowledges the support of the Farr Institute.

Contributors from the Scottish Health and Ethnicity Linkage Study research team: these contributors served on the Steering Group and some on other important subgroups of SHELS, and therefore gave general direction that helped this analysis. Chris Povey was a co-applicant and the originator of the idea of linking the census data to the data held by ISD and he performed most of the linkage work, including developing linkage 
methods. Prof Jamie Pearce (co-applicant) advised especially on socioeconomic adjustment. Duncan Buchanan (co-applicant) chaired the analysis subgroup. Ganka Mueller (part study), Alex Stannard (part study) and Kirsty MacLachlan advised particularly in relation to National Records of Scotland contributions. These important contributions did not meet ICMJE authorship requirements.

\section{Funding}

Chief Scientist's Office of the Scottish Government, British Lung Foundation and NHS Health Scotland.

\section{Author details}

'Edinburgh Migration, Ethnicity and Health Research Group, Usher Institute of Population Health Sciences and Informatics, The University of Edinburgh, Teviot Place, Edinburgh EH8 9AG, UK. ${ }^{2}$ Asthma UK Centre for Applied Research, Usher Institute of Population Health Sciences and Informatics, The University of Edinburgh, Edinburgh, UK. ${ }^{3}$ Division of General Internal Medicine and Primary Care and Department of Medicine, Harvard Medical School, Boston, MA, USA. ${ }^{4}$ Department of Child Health, School of Medicine, University of Aberdeen, Aberdeen, UK. ${ }^{5}$ Cardiovascular Epidemiology Unit, The Department of Public Health and Primary Care, University of Cambridge, Cambridge, UK. ${ }^{6} \mathrm{NHS}$ National Services Scotland, Edinburgh, UK.

Received: 6 July 2015 Accepted: 17 December 2015

Published online: 12 January 2016

\section{References}

1. Masoli M, Fabian D, Holt S, Beasley R. Global burden of asthma. www. ginasthma.org/local/uploads/files/GINABurdenReport_1.pdf. Accessed 28 June 2015.

2. The International Study of Asthma and Allergies in Childhood (ISAAC) Steering Committee. Worldwide variation in prevalence of symptoms of asthma, allergic rhinoconjunctivitis, and atopic eczema: ISAAC. Lancet. 1998; 351:1225-32.

3. Pearce N, Sunyer J, Cheng S, Chinn S, Björkstén B, Burr M, et al. Comparison of asthma prevalence in the ISAAC and the ECRHS. ISAAC Steering Committee and the European Community Respiratory Health Survey. International Study of Asthma and Allergies in Childhood. Eur Respir J. 2000;16:420-6.

4. Royal College of Physicians. Why asthma still kills. The National Review of Asthma Deaths (NRAD). http://www.rcplondon.ac.uk/sites/default/files/whyasthma-still-kills-full-report.pdf. Accessed 28 June 2015.

5. Anandan C, Gupta R, Simpson CR, Fischbacher C, Sheikh A. Epidemiology and disease burden form allergic disease in Scotland: analyses of national databases. J R Soc Med. 2009;102:431-42.

6. Zoratti EM, Havstad S, Rodriguez J, Robens-Paradise Y, Lafata JE, McCarthy B. Health service use by African Americans and Caucasians with asthma in a managed care setting. Am J Respir Crit Care Med. 1998;158:371-7.

7. Clement LT, Jones CA, Cole J. Health disparities in the United States: childhood asthma. Am J Med Sci. 2008;335:260-5.

8. Hill TD, Graham LM, Divgi V. Racial disparities in pediatric asthma: a review of the literature. Curr Allergy Asthma Rep. 2011;11:85-90.

9. Martinez FD, Vercelli D. Asthma. Lancet. 2013:382:1360-72.

10. Patient-Centered Outcomes Research Institute. http://www.pcori.org/content/ pcori-approves-23-million-research-reduce-disparities-asthma-burden-andoutcomes. Accessed 28 June 2015.

11. Netuveli G, Hurwitz B, Levy M, Fletcher M, Barnes G, Durham SR, et al. Ethnic variations in UK asthma frequency, morbidity, and health-service use: a systematic review and meta-analysis. Lancet. 2005;365:312-7.

12. Simpson CR, Sheikh A. Epidemiology of asthma: a worldwide perspective. In: Bernstein JA, Levy ML, editors. Clinical asthma: theory and practice. Boca Raton, FL: CRC Press; 2014. p. 3-12.

13. Bhopal R, Fischbacher C, Povey C, Chalmers J, Mueller G, Steiner M, et al. Cohort profile: Scottish Health and Ethnicity Linkage Study of 4.65 million people exploring ethnic variations in disease in Scotland. Int J Epidemiol. 2011:40:1168-75.

14. The Scottish Government. Analysis of ethnicity in the 2001 Census - summary report. http://www.gov.scot/publications/2004/02/18876/32939. Accessed 28 June 2015

15. World Health Organization. International Classification of Diseases. http:// www.who.int/classifications/icd/en/. Accessed 28 June 2015.
16. The Scottish Government. Scottish Index of Multiple Deprivation: guidance and analysis. http://www.gov.scot/Topics/Statistics/SIMD/GuidanceAnal. Accessed 28 June 2015.

17. Fischbacher CM, Cezard G, Bhopal RS, Pearce J, Bansal N. Measures of socioeconomic position are not consistently associated with ethnic differences in cardiovascular disease in Scotland: methods from the Scottish Health and Ethnicity Linkage Study (SHELS). Int J Epidemiol. 2014;43:129-39.

18. Netuveli G, Hurwitz B, Sheikh A. Ethnic variations in incidence of asthma episodes in England \& Wales: national study of 502,482 patients in primary care. Respir Res. 2005;6:120.

19. Bhopal RS, Bansal N, Fischbacher CM, Brown H, Capewell S. Ethnic variations in heart failure: Scottish Health and Ethnicity Linkage Study (SHELS). Heart. 2012;98:468e473.

20. Simpson CR, Sheikh A. Understanding the reasons for poor asthma outcomes in ethnic minorities: welcome progress, but important questions remain Clin Exp Allergy. 2007;37:1730-2.

21. Griffiths C, Kaur G, Gantley M, Feder G, Hillier S, Goddard J, et al. Influences on hospital admission for asthma in south Asian and white adults: qualitative interview study. BMJ. 2001;323:962-6.

22. Lakhanpaul M, Bird D, Manikam L, Culley L, Perkins G, Hudson N, et al. A systematic review of explanatory factors of barriers and facilitators to improving asthma management in South Asian children. BMC Pub Health. 2014;14:403.

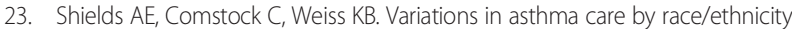
among children enrolled in a state Medicaid program. Pediatrics. 2004;113: 496-504.

24. Norredam M, Hansen OH, Petersen JH, Kunst AE, Kristiansen M, Krasnik A, et al. Remigration of migrants with severe disease: myth or reality?-a register-based cohort study. Eur J Public Health. 2015;25:84-9.

25. Simpson CR, Ritchie LD, Robertson C, Sheikh A, McMenamin J. Effectiveness of H1N1 vaccine for the prevention of pandemic influenza in Scotland, UK: a retrospective observational cohort study. Lancet Inf Dis. 2012;12:696-702.

26. Davidson E, Liu JJ, Sheikh A. The impact of ethnicity on asthma care. Prim Care Respir J. 2010;19:202-8.

27. Napier AD, Ancarno C, Butler B, Calabrese J, Chater A, Chatterjee H, et al. Culture and health. Lancet. 2014;384:1607-39.

\section{Submit your next manuscript to BioMed Central and we will help you at every step:}

- We accept pre-submission inquiries

- Our selector tool helps you to find the most relevant journal

- We provide round the clock customer support

- Convenient online submission

- Thorough peer review

- Inclusion in PubMed and all major indexing services

- Maximum visibility for your research

Submit your manuscript at www.biomedcentral.com/submit
Biomed Central 